\title{
Zinc Homeostasis in Premature Infants Does Not Differ Between Those Fed Preterm Formula or Fortified Human Milk
}

\author{
SANJU JALLA, NANCY F. KREBS, DONNA RODDEN, AND K. MICHAEL HAMBIDGE \\ Johns Hopkins Oncology Center [S.J.], Johns Hopkins University, Baltimore, Maryland 21231, Section of \\ Nutrition, Department of Pediatrics [N.F.K., K.M.H.], and Pediatric General Clinical Research Center \\ [D.R.], University of Colorado Health Sciences Center, Denver, Colorado, 80262
}

\begin{abstract}
ABSTR
The objectives of this study were to compare zinc homeosta-
sis in premature infants enterally fed with either preterm infant
formula or fortified human milk; to examine interrelationships of
variables of zinc homeostasis; and to examine the findings in
relation to estimated zinc requirements of preterm infants. Zinc
homeostasis was studied in 14 infants ( 8 male), with mean
gestational age of 31 wk and birth weight appropriate for gesta-
tional age, who were exclusively fed either preterm formula ( $n=$
9) or own mother's milk with human milk fortifier ( $n=5$ ). Zinc
stable isotopes were administered intravenously ( $\left.{ }^{70} \mathrm{Zn}\right)$ and
orally as an extrinsic label ( $\left.{ }^{67} \mathrm{Zn}\right)$ over multiple feeds for deter-
mination of fractional absorption by dual isotope tracer ratio in
urine; endogenous fecal zinc was determined by isotope dilution;
and exchangeable zinc pool (EZP) size was estimated from linear
regression of log-transformed urine ${ }^{70} \mathrm{Zn}$ enrichment data. Re-
sults indicated no significant differences in the variables of zinc
\end{abstract}
homeostasis between the feeding groups; data for all subjects were thus combined. Mean $( \pm \mathrm{SD})$ fractional absorption was $0.26 \pm 0.07$; net absorbed zinc $0.43 \pm 0.25 \mathrm{mg} / \mathrm{d}(0.31 \pm 0.19$ $\mathrm{mg} / \mathrm{kg} / \mathrm{d}$ ). Mean EZP was $20 \pm 10 \mathrm{mg} / \mathrm{kg}$, and was positively correlated with total absorbed zinc and with net absorbed zinc. Feeding type and total absorbed zinc were significantly related to daily weight gain $(p=0.003)$. Current zinc intakes from fortified human milk or formula are associated with acceptable weight gain, but whether the observed net zinc absorption was optimal in the human milk group cannot be definitively determined from these data. (Pediatr Res 56: 615-620, 2004)
EZP, exchangeable zinc pool
HM+HMF, human milk + human milk fortifier
PTF, preterm formula

Abbreviations
Premature infants have relatively high zinc dietary requirements and face special challenges to meet them for several reasons. About $60 \%$ of fetal zinc is acquired during the third trimester of pregnancy, when fetal weight increases 3-fold. Preterm infants ( $<37 \mathrm{wk}$ gestation) have lower zinc reserves than term infants and because of immaturity, they may be less efficient at absorbing and retaining zinc for growth $(1,2)$. Achievement of intrauterine growth rates and accretion of lean body mass dictates a zinc retention rate that has been estimated to be as high as $850 \mu \mathrm{g} / \mathrm{d}$ (3). If infants can access the zinc associated with hepatic metallothionein, as has been proposed (4), there is likely to be less available zinc to the preterm infant, for whom the hepatic metallothionein concentration is higher

Received February 11, 2003; accepted September 5, 2003.

Correspondence: Nancy F. Krebs, M.D., Department of Pediatrics, University of Colorado School of Medicine, 4200 East Ninth Ave., Box C225, Denver, CO 80262; e-mail: Nancy.Krebs@uchsc.edu

Supported by grants from the National Institutes of Health (Pediatric General Clinical Research Center RR00069, K08-DK02240, Clinical Nutrition Research Unit P30-DK48520) and from Nestle Nutrition Fellowship.

DOI: 10.1203/01.PDR.0000139428.77791.3D but the absolute amount present is less than for term infants. The gastrointestinal tract is the major site of regulation of zinc homeostasis and involves both absorption of exogenous zinc and secretion and reabsorption of endogenous zinc. Adequate absorption may be compromised by limited intake, and possibly by immature digestive and absorptive processes. Excessive endogenous losses may also occur, secondary either to poorly regulated secretion or to interference with reabsorption.

It is standard practice in most centers caring for premature infants to use either human milk with human milk fortifier or nutrient enriched formulas, both of which are specifically designed for preterm infants and which include generous zinc fortification. Studies of zinc homeostasis in premature infants to date have been somewhat conflicting regarding zinc requirements and the optimal daily zinc intake in this population $(1,2,5-7)$. The objectives of this study were to compare zinc homeostasis in premature infants fed either premature infant formula or fortified human milk; to examine interrelationships of variables of zinc homeostasis, including size of EZP; and to examine the findings in relation to estimated zinc requirements of preterm infants. 


\section{METHODS}

Study design. This was a cross-sectional study, which compared zinc homeostasis between premature infants fed either PTF or HM+HMF. Stable zinc isotopes were administered intravenously and orally on $\mathrm{d} 1 ; 3 \mathrm{~d}$ later, a metabolic period was initiated, which included measurement of formula or milk intake for $3 \mathrm{~d}$, and complete urine and fecal collections for approximately $5 \mathrm{~d}$ (depending on passage of second fecal marker). Fractional absorption of zinc was measured by dual isotope tracer ratio in urine (8); and endogenous fecal zinc was determined by isotope dilution (9). Quantitative measurements of zinc intake from milk or formula and urine zinc excretion were combined with isotopic measurements to determine net zinc absorption and retention. The studies were undertaken in the Newborn Intensive Care Unit, University of Colorado Hospital through the Pediatric General Clinical Research Center (PGCRC).

Subjects. We studied a convenience sample of 14 hospitalized preterm infants with a mean gestation age of $30.9 \pm 1.7$ wk (range, 27-34 wk) and a mean birth weight of $1230 \pm$ $254 \mathrm{~g}$ (range, 705-1700 g). Entry criteria included infant being on full enteral feeds exclusively of one type (human milk or formula) for the entire study period ( $8 \mathrm{~d}$ ); mother being able to provide breast milk for the entire study period for the infants who were on breast milk; birth weight $<1800 \mathrm{~g}$ and appropriate-for-gestational-age; and gestational age $<35 \mathrm{wk}$. Infants were studied between 1991 and 1998. Subject recruitment was halted at this time because of major reformulation of HMF in 1998, which would have required conducting studies in at least an equal number of additional infants receiving $\mathrm{HM}+\mathrm{HMF}$, and thus would have further extended the study period. After careful explanation of the purpose and the procedures of the study, consent was obtained from all subjects' parents. The study and procedures were approved by the Colorado Multiple Institutional Research Review Board.

Dietary intake. Nine of the infants were fed a commercial formula specifically intended for premature infants with energy density 24 kcal/oz (Enfamil Premature Formula, Mead Johnson Nutritionals, Evansville, IN). Five infants were fed their own mother's expressed milk, which was fortified with human milk fortifier (Mead Johnson Nutritionals), made according to manufacturer's instructions to achieve $24 \mathrm{kcal} / \mathrm{oz}$. The nutritional composition of the formula and human milk fortifier is provided in Table 1. There were no substantial changes in either of these formulations during the time frame of this study. Exact feeding schedule was determined by the neonatology service but feeds were held constant during the study period. All infants received bolus feedings by gavage, spaced at least by $2 \mathrm{~h}$, more typically every $3 \mathrm{~h}$. Intake of milk was quantified by pre- and post-weighing of gavage feeding sets (tubing + syringe) on a digital electronic balance accurate to $0.01 \mathrm{~g}$. During the metabolic period, regurgitations were collected on ashless filter papers in the isolette under the infant's face. These were removed immediately and weighed by the nursing staff and the weight subtracted from the intake. Filter papers were kept under the infant's face at all times throughout the study and all collections were analyzed for total zinc content.
Table 1. Nutrient composition (per $100 \mathrm{~mL}$ ) of preterm formula and estimated content of preterm human milk fortified with human milk fortifier

\begin{tabular}{|c|c|c|}
\hline & $\begin{array}{l}\text { Preterm } \\
\text { formula }\end{array}$ & $\begin{array}{c}\text { Preterm } \\
\mathrm{HM}+\mathrm{HMF}\end{array}$ \\
\hline Energy (kcal) & 80 & 80 \\
\hline Protein (g) & 2.4 & 2.3 \\
\hline Fat $(\mathrm{g})$ & 4.1 & 3.5 \\
\hline Carbohydrate (g) & 8.9 & 10 \\
\hline \multicolumn{3}{|l|}{ Vitamins } \\
\hline A (IU) & 1000 & 1000 \\
\hline $\mathrm{D}(\mathrm{IU})$ & 216 & 220 \\
\hline E (IU) & 5.4 & 5 \\
\hline $\mathrm{K}(\mu \mathrm{g})$ & 6.4 & 6.4 \\
\hline Thiamin $(\mu \mathrm{g})$ & 160 & 160 \\
\hline Riboflavin $(\mu \mathrm{g})$ & 240 & 240 \\
\hline $\mathrm{B} 6(\mu \mathrm{g})$ & 120 & 120 \\
\hline $\mathrm{B} 12(\mu \mathrm{g})$ & 0.2 & 0.2 \\
\hline Niacin $(\mu \mathrm{g})$ & 3200 & 3200 \\
\hline Folic acid $(\mu \mathrm{g})$ & 28 & 28 \\
\hline $\mathrm{C}(\mathrm{mg})$ & 16 & 16 \\
\hline \multicolumn{3}{|l|}{ Minerals } \\
\hline Calcium (mg) & 132 & 115 \\
\hline Phosphorus (mg) & 66 & 60 \\
\hline Magnesium (mg) & 5.4 & 4.3 \\
\hline Iron $(\mathrm{mg})$ & 0.2 & 0.09 \\
\hline Zinc (mg) & 1.3 & 1.08 \\
\hline Manganese $(\mu \mathrm{g})$ & 5.5 & 5.1 \\
\hline Copper $(\mu \mathrm{g})$ & 100 & 100 \\
\hline Iodine $(\mu \mathrm{g})$ & 20.8 & 17.8 \\
\hline Sodium (mg) & 31 & 35 \\
\hline Potassium (mg) & 82.4 & 66 \\
\hline Chloride (mg) & 68 & 76 \\
\hline
\end{tabular}

A 5-mL sample of fortified human milk was obtained for zinc analysis from each feed during the metabolic period. Aliquots of formula were also obtained from each bottle of formula for zinc analysis.

Isotope preparation and administration. Zinc oxide powders enriched with ${ }^{70} \mathrm{Zn}(99.72 \%$ abundance $)$ and ${ }^{67} \mathrm{Zn}(89.55 \%$ abundance), which were obtained from Oak Ridge National Laboratories (Oak Ridge, TN), were prepared using standard sterile techniques. Accurately weighed quantities of the isotope were dissolved in $1 \mathrm{~N} \mathrm{H}_{2} \mathrm{SO}_{4}$, diluted in triply de-ionized water, titrated with metal-free ammonium hydroxide to a $\mathrm{pH}$ of 6 for the i.v. preparation and a $\mathrm{pH}$ of 5 for oral preparation. The concentration of zinc in the isotope preparation was determined in triplicate by atomic absorption spectrophotometry, with correction made for the higher atomic weight of the enriched zinc. The ${ }^{70} \mathrm{Zn}$ preparation was tested for pyrogens (Limulus Amebocyte Lysate Kit, Whittaker Bioproducts, Walkersville, MD) within $24 \mathrm{~h}$ before i.v. administration.

Nursing records were examined before starting the study to calculate the infants' habitual zinc intake. A 24-h batch of the infant's diet (formula or expressed human milk) was extrinsically labeled with accurately weighed doses of ${ }^{67} \mathrm{Zn}$ (approximately $300 \mu \mathrm{g}$ to equal approximately $10 \%$ of the infant's estimated daily zinc intake) and allowed to equilibrate for at least $4 \mathrm{~h}$ before the first feeding. An accurately weighed amount of ${ }^{70} \mathrm{Zn}$ (approximately $40 \mu \mathrm{g} / \mathrm{kg}$ of body weight) was quantitatively infused over $10 \mathrm{~min}$ on $\mathrm{d} 1$ of the study. This was followed by repeated rinsing of the syringe to assure that 
the complete dose was administered. On the same day, $2 \mathrm{~h}$ after ${ }^{70} \mathrm{Zn}$ administration, ${ }^{67} \mathrm{Zn}$ was given with four to eight gavage feeds over 12-24 h period. Gavage feeding sets of labeled human milk or formula were weighed to the nearest $0.01 \mathrm{~g}$ before and after each feed to determine amount of labeled formula ingested. Regurgitations during the labeled feeds were collected on the ashless filter papers. Total zinc and isotope enrichment were subsequently determined on the regurgitations and subtracted from the administered dose. On d 4, a brilliant blue marker $(\sim 1 \mathrm{mg} / \mathrm{kg})$ was mixed with a small amount of milk or formula and given with one feed. A second marker labeled feed was given $72 \mathrm{~h}$ later to demarcate the metabolic period.

Metabolic collections. Clinical care and study procedures were conducted by the PGCRC neonatal nurses throughout the study, and the infants were in state-of-the-art, thermalregulated isolettes, which had been cleaned before the study with cation-free detergent. Zinc-free plastic sheeting was also placed on the mattresses over which the infants were placed. During the study, the PGCRC nurses maintained strict precautions to avoid zinc contamination of the infant's skin, collection materials, or isolette. Baseline stool and urine collections were obtained before isotope administration on $\mathrm{d} 1$. During the metabolic period, stools were collected directly onto ashless filter papers, which were immediately removed and stored in marked plastic, sealable bags that were labeled with infant number, date, and time of specimen collection. Fecal collections were continued until passage of the second brilliant blue marker. Continuous urine collections were also obtained in 12-h pools on $\mathrm{d}$ 4-8. A plastic resealable bag was adhered to the infant's skin with tape over an adherent patch (Stomadhesive Wafer, Squibb, Inc., New Brunswick, NJ). Daily naked weights were obtained on electronic balances each morning throughout the study.

Laboratory analyses. Milk, stool, and urine analyses for total zinc and isotopic enrichment were performed as previously described (10-12). Stools were ashed in the muffle furnace at $425^{\circ} \mathrm{C}$, wet digested with concentrated nitric acid, and re-ashed. The ashed samples were quantitatively dissolved in $6 \mathrm{~N} \mathrm{HCl}$ and total zinc was determined with an atomic absorption spectrophotometer (AAS) fitted with a deuterium arc background correction lamp (PerkinElmer Instruments, Norwalk, CT).

Zinc was separated from other inorganic elements by ion exchange chromatography with AG 1 ion exchange resin (BioRad Laboratories, Richmond, CA). Percent isotopic enrichment was then determined by fast atom bombardment-induced secondary ion mass spectrometry on a double-focusing mass spectrometer (model VG 7070E HF; Fisons-VG Analytical, Manchester, UK) equipped with an Ion Tech (London, UK) atom gun. The mass spectrometer was operated at low resolution, and ion counting detection and peak switching were used to measure ${ }^{70} \mathrm{Zn} /{ }^{66} \mathrm{Zn}$ and ${ }^{67} \mathrm{Zn} /{ }^{66} \mathrm{Zn}$ ratios; sample enrichments were derived using a standard curve (13).

Processing of urine samples included wet digestion, followed by ashing in muffle furnace. Reconstituted ash was applied to chelating resin and ion exchange columns to remove other mineral elements (8). Isotopic enrichment in the resulting solutions was measured as described above. Samples of enriched milk and regurgitated milk on filter papers were processed by similar methods as for fecal samples, and total zinc and isotopic enrichment likewise determined. Zinc concentrations were determined for aliquots from each human milk feed or for formulas by ashing samples and determining zinc concentration by AAS.

Calculations. Total dietary zinc intake $(\mathrm{mg} / \mathrm{d})$ was determined by multiplying zinc concentration of human milk or formula by grams of milk per feed between markers.

Fractional absorption was determined from the mean of the ratio of the urine enrichments of the oral isotope to the i.v. isotope measured after $\mathrm{d} 3$, taking into account the size of the isotope doses (8). Total absorbed zinc $(\mathrm{mg} / \mathrm{d})$ was calculated by multiplication of dietary zinc and fractional absorption.

Excretion of endogenous fecal zinc $(\mathrm{mg} / \mathrm{d})$ was determined by isotope dilution method according to the formula of Sigma Chemical Co. (St. Louis, MO): $\Sigma F \cdot f /(u \cdot d)$, where $F=$ the total $\mathrm{Zn}$ in each fecal sample collected between the appearance of colored fecal markers; $f=$ enrichment of i.v. isotope $\left({ }^{70} \mathrm{Zn}\right)$ in corresponding fecal sample; $\mathrm{u}=$ average enrichment in urine of i.v. isotope during the marker period; and $d=$ time (3 d) during metabolic collections (9). Net absorption of zinc was calculated as the difference between total absorbed zinc and endogenous fecal zinc. Net retention of zinc was calculated as the net absorption minus 24-h urine zinc excretion.

The EZP is defined as the estimate of the total size of the combined pools of zinc that exchange with zinc in plasma within approximately $2-3$ d. The EZP was calculated by dividing the mass of i.v. isotope dose by the enrichment value at the y-intercept of the linear regression of a semi-log plot of urine enrichment data from $\mathrm{d} 4$ to 8 after isotope administration (14).

Data analysis. The analyses were performed with SPSS 11.5 for Windows (SPSS Inc., Chicago, IL), and by GraphPad Prism 3.01 (GraphPad Software, San Diego CA). The variables of zinc homeostasis were compared between feeding groups using independent $t$ test. Univariate correlations were performed among variables of interest. To evaluate predictors of weight gain, linear regression analysis was performed with independent variables of feeding group, dietary zinc intake, absorbed zinc, and net absorbed zinc. Stepwise regression was also performed on these variables. Data are presented as mean $\pm \mathrm{SD}$, except where noted when feeding groups are being compared. Statistical significance was considered at $p$ value $<0.05$.

\section{RESULTS}

The demographic characteristics of the preterm infants within each group are provided in Table 2. Mean ( \pm SD) gestational age for all subjects was $30.8 \pm 1.7 \mathrm{wk}$, and all had birth weight appropriate for gestational age. There were no significant differences between the groups for any of the characteristics at baseline. Weight gain during the $8 \mathrm{~d}$ of the study averaged $25.7 \pm 8.9 \mathrm{~g} / \mathrm{d}(18.9 \pm 6.6 \mathrm{~g} / \mathrm{kg} / \mathrm{d})$, with averages of $29 \pm 9$ and $19 \pm 5 \mathrm{~g} / \mathrm{d}$ for the PTF and HM + HMF groups, respectively. For the PTF group, mean daily intake of formula was $156 \pm 14 \mathrm{~g} / \mathrm{kg} / \mathrm{d}$; for the HM+HMF group, mean intake 
Table 2. Demographic characteristics (mean $\pm S D)$ by group at

\begin{tabular}{lcc}
\multicolumn{3}{c}{ study entry } \\
\hline \multicolumn{1}{c}{ Characteristics } & $\begin{array}{c}\text { Preterm formula } \\
(n=9)\end{array}$ & $\begin{array}{c}\text { HM }+ \text { HMF } \\
(n=5)\end{array}$ \\
\hline Sex (male:female) & $4: 5$ & $4: 1$ \\
Birth weight (g) & $1154 \pm 310$ & $1305 \pm 146$ \\
Gestational age (wk) & $30.6 \pm 2.2$ & $30.8 \pm 1.1$ \\
Age at start of study (wk) & $32.9 \pm 1.6$ & $32.8 \pm 1.6$ \\
Weight at start of study $(\mathrm{g})$ & $1335 \pm 250$ & $1490 \pm 205$ \\
\hline
\end{tabular}

was $167 \pm 13 \mathrm{~g} / \mathrm{kg} / \mathrm{d}$; and for both groups combined intake was $160 \pm 14 \mathrm{~g} / \mathrm{kg} / \mathrm{d}$.

The means for the two groups for the variables of zinc homeostasis are presented in Table 3. There was no significant difference for any variable between the PTF and HM+HMF groups; the data were thus combined for further analyses. Mean urine zinc excretion was $27 \pm 15 \mu \mathrm{g} / \mathrm{kg} / \mathrm{d}$. All infants achieved a positive net absorption and net retention. The size of the EZP also did not differ between groups; the combined mean was $28 \pm 16 \mathrm{mg}(20 \pm 10 \mathrm{mg} / \mathrm{kg})$.

Examination of interrelationships among variables of zinc homeostasis revealed total absorbed zinc was strongly positively correlated with net absorption $(r=0.94, p<0.001)$. By univariate analyses, dietary zinc intake, total absorbed zinc, and net absorbed zinc were each significantly positively correlated with daily weight gain $(r=0.70, r=0.61$, and $r=$ 0.56 , respectively; $p \leq 0.04$ ) (Fig. 1). When weight gain was examined as the independent variable and net retention of zinc as dependent variable, linear regression was also significant ( $p=0.037)$ (Fig. 2). Similar correlations were seen with daily weight gain relative to body weight. No correlation was observed between daily intake of formula or fortified human milk and weight gain (data not shown). This appears to be due to a lack of significant correlation between zinc intake and daily volume of intake for the human milk-fed infants $(r=0.19)$, whereas, as expected, there was a strong correlation between zinc intake and volume for the formula-fed infants $(r=0.91)$. With stepwise regression, the model including feeding group and total absorbed zinc as independent variables, and weight gain as dependent variable, showed the strongest significance $(p=0.003)$, with $r^{2}=0.66$.

Total absorbed and net absorption were both positively correlated with total EZP: $r=0.64$ and 0.58 , respectively $(p=$

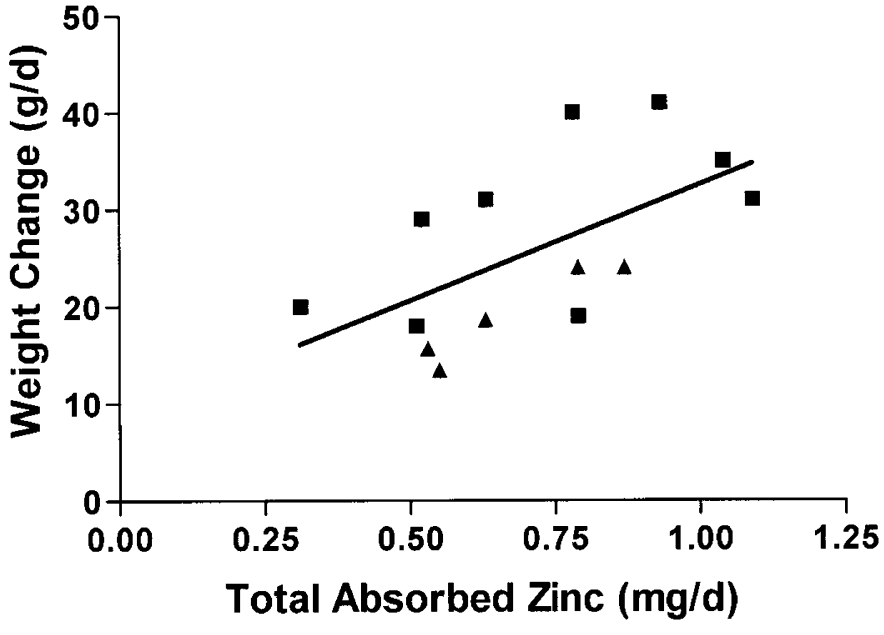

Figure 1. Linear regression between daily weight gain $(\mathrm{g} / \mathrm{d})$ and total absorbed zinc (mg/d) for premature infants fed preterm formula (squares) or human milk with human milk fortifier (triangles). Regression equation: $\mathrm{y}=$ $8.6+24.0(\mathrm{x}) ;(p=0.02)$.

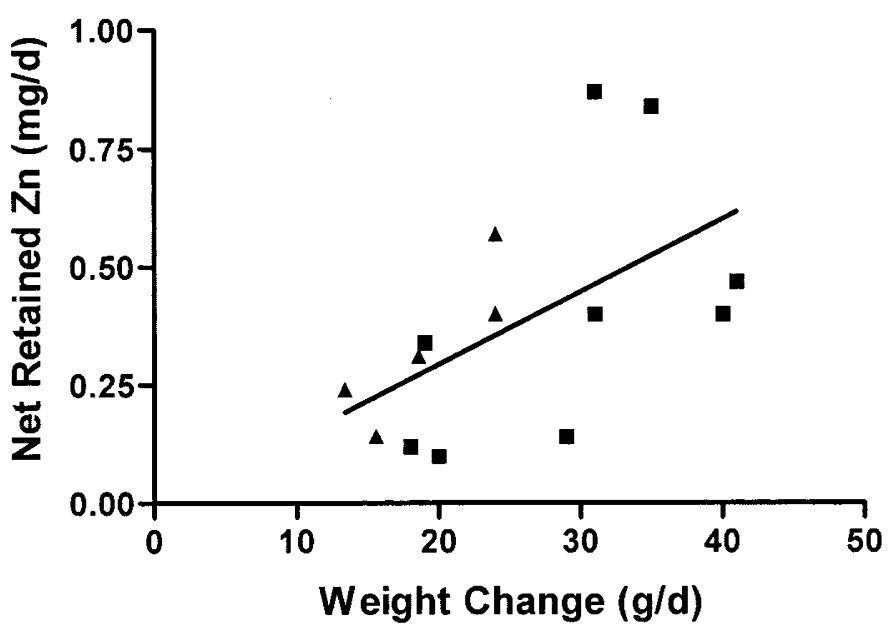

Figure 2. Linear regression between net retained zinc $(\mathrm{mg} / \mathrm{d})$ and weight gain $(\mathrm{g} / \mathrm{d})$ for premature infants fed preterm formula (squares) or human milk with human milk fortifier (triangles). Regression equation: $\mathrm{y}=-0.014+0.015(\mathrm{x})$; $(p=0.037)$.

0.01 and 0.03 , respectively). In contrast to findings in term infants, endogenous fecal zinc was not correlated with total absorbed zinc or with EZP. Multivariate regression with en-

Table 3. Summary of intake and absorption of zinc by feeding group and for all subjects (mean \pm SEM)

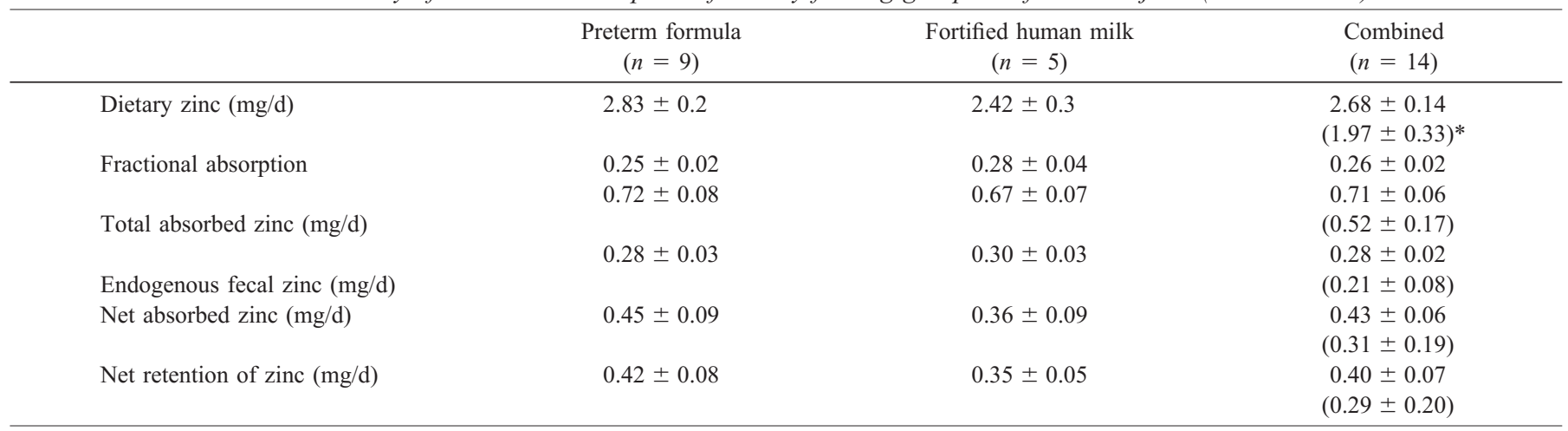

* Numbers in parentheses indicate value relative to body weight $(\mathrm{kg})$, mean $\pm \mathrm{SD}$. 
dogenous fecal zinc as dependent variable also showed no independent effect of gestational age, birth weight, or group.

\section{DISCUSSION}

The estimated requirement for the amount of zinc to be retained from dietary zinc, based on nonhepatic retention minus modest release from hepatic zinc stores, has been estimated to be approximately $600 \mu \mathrm{g} / \mathrm{d}(2)$. The mean retention for the infants in this study was substantially less than that, and yet rates of weight gain were acceptable. A key consideration, therefore, for these data are whether the zinc intake and retention were adequate, and, accordingly whether previous estimates for required retention have been too generous.

The total dietary zinc in this study was generous relative to current recommendations of $0.6-1.7 \mathrm{mg} / \mathrm{kg} / \mathrm{d}(2,15)$, but was similar to intake in several other studies $(5,7,16)$. The addition of human milk fortifier to the expressed human milk provided intakes well within the recommended range and to levels that were $\sim 85 \%$ of those fed the preterm infant formula. For comparison, the zinc intakes of these preterm infants, on a body weight basis, were nearly double that of term formula fed infants (17), and 5- to 6-fold that of term breast-fed infants (11).

The observed mean fractional absorption was somewhat lower than that reported from fecal monitoring technique or compartmental modeling $(5,18)$, but was quite comparable to values reported by Friel et al. (7), who also measured fractional absorption by the dual isotope tracer ratios in urine method. For the fecal monitoring method used in other studies, incomplete fecal collections, due either to slower than expected fecal transit time over the collection period or to losses associated with the collection process, result in overestimation of fractional absorption. We suspect that this methodological difference is likely to account for at least some of the differences among reports.

In this study, we did not find differences between infants fed preterm formula versus those fed fortified human milk, which is in contrast to an earlier report that fractional absorption from preterm formula was lower than from fortified human milk (5). The explanation for the differences in findings between this study in preterm infants and that of Ehrenkrantz et al. (5) cannot be determined with certainty. Potential differences in fecal transit in formula-fed compared with human milk-fed infants would also imply differences in passage of unabsorbed isotope, which may not have been detected within the predetermined time frame $(3 \mathrm{~d})$ of the fecal collections in the Ehrenkrantz study. If the human milk-fed infants had a slower transit time, this would have been a bias toward erroneously high estimates of fractional absorption in the infants fed fortified human milk. Differences in the composition of either the formula or the human milk fortifier between the earlier study and the present one may also have contributed to differences in fecal transit time and/or of bioavailability of zinc. We suggest that the absence of difference in fractional absorption is likely due to the equivalent zinc intake for the two feeding types resulting from the zinc fortification with zinc sulfate in both the formula and human milk.
Endogenous fecal zinc excretion measured in this study by isotope dilution was considerably lower than in several previous reports in premature infants $(5,7)$, but was nearly twice that of term formula-fed infants (17) and approximately 4-fold greater than that of term exclusively breast-fed infants (11). Methodological differences may again account for differences between studies in preterm infants, since some have relied on a difference of net absorption, derived from mass balance data, and absorbed zinc determined with stable isotopes (5). The challenges of obtaining accurate balance data are well recognized. The question remains, however, whether the amount of endogenous fecal zinc in the present study is relatively high because of the very high intake, or whether the premature infant has limited ability to conserve the amount of zinc secreted endogenously and/or to reabsorb this zinc. The former explanation suggests that the intakes observed here, which are typical for current clinical management, and the amount of absorbed zinc are adequate, and there was no physiologic effort to conserve more intestinal endogenous zinc to achieve a greater net absorption to support a greater accretion. Alternatively, if there is limited capacity to conserve endogenous intestinal zinc, an even greater intake would be necessary to achieve a more positive net retention. The lack of correlation between the amount of absorbed zinc and the endogenous fecal zinc, a relationship observed in both normal adults and infants (19-21), suggests some inefficiency. For example, fat malabsorption has been associated with excessive excretion of endogenous fecal zinc (12), and with negative zinc balance in preterm infants (22).

The mean net absorption and net retention of zinc for these infants were comparable to the fetal accumulation in the third trimester of $250 \mu \mathrm{g} / \mathrm{d}$ proposed by Shaw (23), but are considerably less than the $850 \mu \mathrm{g} / \mathrm{d}$ proposed by Widdowson et al. (3). Estimate of the zinc required for lean tissue accumulation is typically $30 \mu \mathrm{g} \mathrm{Zn} / \mathrm{g}$, and $20 \mu \mathrm{g} \mathrm{Zn} / \mathrm{g}$ of tissue of mixed composition (24), but has been proposed to be considerably higher in the fetus (2). As predicted by the regression in Figure 2 , the net zinc retention and the weight gain observed in these infants suggests $\sim 15 \mu \mathrm{g} \mathrm{Zn/g}$ of new tissue, which is low by any standard. The composition of the weight gain was not measured in the present study and may have represented a relatively higher accumulation of adipose tissue or other components, which might be lower in zinc concentration. The composition of weight gain for the preterm infant compared with the fetus or to the term infant has been proposed to be considerably higher in fat $(2,25)$. If the higher figure for fetal zinc accumulation is accurate, that would suggest that these infants are not retaining similar amounts of zinc in some tissues, e.g. in bone.

Although the rate of weight gain is in an acceptable range for clinical management, the correlations between dietary, absorbed, and retained zinc and weight gain raise the consideration of whether more positive intake, and thus net retention, would result in even greater weight gain. Volume of intake was not related to weight gain, but this was mainly explained by the infants who were fed fortified human milk, for whom zinc intake, and possibly other nutrients, was more variable for a given volume compared with the formula-fed infants. If such 
was the case, zinc may be a "proxy" for another nutrient, which instead may have been limiting growth. In addition, there may also have been differences in absorption and utilization of other nutrients, such as fat, which were not examined. Thus, caution is warranted in concluding that a greater zinc intake alone would result in greater weight gain, and/or greater zinc accumulation.

Model-based compartmental analysis of zinc metabolism in adults has identified several pools of zinc, including that in the liver, that intermix with the zinc in plasma within $3 \mathrm{~d}$, the combined size of which we have termed the EZP (14). The size of the EZP relative to body weight is higher in these preterm infants than in any other group we have studied. For example, EZP size determined after adjustment for orally administered isotopes in 2- to 4-mo-old term breast-fed infants averaged 5 $\mathrm{mg} / \mathrm{kg}$, whereas that of term formula-fed infants at similar ages was $15 \mathrm{mg} / \mathrm{kg}$ (26). The high EZP mass in these premature infants seems likely to reflect the relatively high total absorbed and net absorbed zinc, both of which were significantly correlated with EZP size and which have also been observed to correlate with EZP both in term infants (26) and in adults (19). The relatively high EZP in the premature infants may also reflect, in part, the zinc bound to hepatic metallothionein, the concentrations of which have been reported to be higher in preterm than term infants, although absolute amounts are less in preterm infants (4). From the data obtained in the present study, the contribution of hepatic metallothionein bound zinc present at birth and contributing to the EZP cannot be distinguished from the contribution from absorbed dietary zinc. Since the majority of the hepatic zinc is presumed to accumulate in the last trimester, however, this source is assumed to be relatively modest.

In summary, these data indicate that usual clinical practice for preterm infants results in zinc intakes that are generous compared with estimated dietary requirements. The bioavailability of the zinc was not detectably different for those fed fortified human milk and for those receiving preterm formula, and both feeding types resulted in an excellent amount of absorbed zinc. Endogenous fecal zinc excretion was also relatively high and was not correlated with the amount of absorbed zinc, suggesting immaturity of or interference with normal regulation of these losses. Net zinc absorption (and retention) was positive in all infants, and was correlated with the size of the EZP. Because the hepatic zinc reserves in these premature infants were likely to be low at birth, the relatively large EZP size demonstrates the potential for substantial postnatal zinc accretion with generous intakes. However, the unexpectedly low amount of zinc retained per gram of weight gain, coupled with the observation that absorbed zinc and feeding group were related to rate of weight gain, raises the question of whether even these zinc intakes and absorption were optimal, particularly in the human milk-fed group. Additional studies will be necessary to assess potential benefit of increasing zinc intake while controlling for confounding factors and monitoring for potential adverse effects. Meanwhile, the findings from this study emphasize the importance of this micronutrient for growth and provide additional data on which to estimate requirements for premature infants.

\section{REFERENCES}

1. Hambidge KM, Krebs NF 2004 Zinc in the fetus and neonate. In: Polin R, Fox W, Abman SH (eds) Fetal and Neonatal Physiology, 3rd Ed. Elsevier Science, Philadelphia, pp 342-346

2. Klein CJ 2002 Nutrient requirements for preterm infant formulas. J Nutr 132:1395S$1577 \mathrm{~S}$

3. Widdowson EM, Southgate DAT, Hey E 1988 Fetal growth and body composition. In: Linblad, BS (ed) Perinatal Nutrition. Academic Press, New York, pp 3-14

4. Zlotkin SH, Cherian MG 1988 Hepatic metallothionein as a source of zinc and cysteine during the first year of life. Pediatr Res 24:326-329

5. Ehrenkrantz RA, Gettner PA, Nelli CM, Sherwonit EA, Williams JE, Ting BTG, Janghorbani M 1989 Zinc and copper nutritional studies in very low birth weight infants: comparison of stable isotopic extrinsic tag and chemical balance methods. Pediatr Res 26:298-307

6. Dauncey MJ, Shaw JCL, Urman J 1977 The absorption and retention of magnesium, zinc, and copper by low birth weight infants fed pasteurized human breast milk. Pediatr Res 11:991-997

7. Friel JK, Andrews WL, Simmons BS, Miller LV, Longerich HP 1996 Zinc absorption in premature infants: comparison of two isotopic methods. Am J Clin Nutr 63:342347

8. Friel J, Naake V, Miller L, Fennessey P, Hambidge KM 1992 The analysis of stable isotopes in urine to determine the fractional absorption of zinc. Am J Clin Nutr 55:473-477

9. Krebs NF, Miller LV, Naake L, Lei S, Westcott JE, Fennessey PV, Hambidge KM 1995 The use of stable isotope techniques to assess zinc metabolism. J Nutr Biochem 6:292-301

10. Krebs NF, Hambidge KM, Jacobs MA, Oliva-Rasbach J 1985 The effects of a dietary zinc supplement during lactation on longitudinal changes in maternal zinc status and milk zinc concentrations. Am J Clin Nutr 41:560-570

11. Krebs NF, Reidinger CJ, Miller LV, Hambidge KM 1996 Zinc homeostasis in breast-fed infants. Pediatr Res 39:661-665

12. Krebs NF, Westcott JE, Arnold TD, Kluger BM, Accurso FJ, Miller LV, Hambidge KM 2000 Abnormalities in zinc homeostasis in young infants with cystic fibrosis. Pediatr Res 48:256-261

13. Peirce P, Hambidge KM, Goss C, Miller L, Fennessey P 1987 The use of fast atom bombardment mass spectrometry for the analysis of zinc stable isotopes in biological samples. Anal Chem 59:2034-2037

14. Miller LV, Hambidge KM, Naake VL, Hong Z, Westcott JL, Fennessey PV 1994 Size of the pools that exchange rapidly with plasma zinc in humans: alternative techniques for measuring and relation to dietary zinc intake. J Nutr 124:268-276

15. American Academy of Pediatrics, Committee on Nutrition 1998 Nutritional needs of preterm infants. In: Kleinman RE (ed) Pediatric Nutrition Handbook, 4th Ed. American Academy of Pediatrics, Elk Grove Village, IL, pp 55-87

16. Tyrala EE 1986 Zinc and copper balances in preterm infants. Pediatrics 77:513-517

17. Krebs NF, Reidinger CJ, Miller LV, Borschel M 2000 Zinc homeostasis in normal infants fed a casein hydrolysate formula. J Pediatr Gastroenterol Nutr 30:29-33

18. Wastney ME, Angelus PA, Barnes RM, Siva Subramanian KN 1999 Zinc absorption, distribution, excretion, and retention by healthy preterm infants. Pediatr Res 45:191196

19. Lei S, Xiang M, Miller LV, Krebs NF, Lei T, Hambidge KM 1996 Zinc absorption and intestinal losses of endogenous zinc in young Chinese women with a marginal zinc intake. Am J Clin Nutr 63:348-353

20. Krebs NF, Westcott JE 2002 Zinc and breastfed infants: if and when is there a risk of deficiency? In: Davis MK, Isaacs CE, Hanson LA, Wright AL (eds) Integrating Population Outcomes, Biological Mechanisms and Research Methods in the Study of Human Milk and Lactation. Kluwer Academic/Plenum Publishers, New York, pp $69-75$

21. Krebs NF, Hambidge KM 2001 Zinc metabolism and homeostasis: the application of tracer techniques to human zinc physiology. Biometals 14:397-412

22. Voyer M, Davakis M, Antener I, Valleur D 1982 Zinc balances in preterm infants. Biol Neonate 42:87-92

23. Shaw JCL 1979 Trace elements in the fetus and young infant. I. Zinc. Am J Dis Child 133:1260-1268

24. Krebs NF, Hambidge KM 1986 Zinc requirements and zinc intakes of breast fed infants. Am J Clin Nutr 43:288-292

25. Reichman B, Chessex P, Putet G, Verellen G, Smith JM, Heim T, Swyer PR 1981 Diet, fat accretion, and growth in premature infants. N Engl J Med 305:1495-1500

26. Krebs NF, Hambidge KM, Westcott J, Miller LV, Sian L, Bell M, Grunwald G 2003 Exchangeable zinc pool size in infants is related to key variables of zinc homeostasis. J Nutr 133:1498S-1501S 